\title{
Social Media Use by Young People Living in Conflict-Affected Regions of Myanmar
}

\author{
Brad Ridout, PhD, ${ }^{1}$ Melyn McKay, PhD, ${ }^{2}$ Krestina Amon, PhD, ${ }^{1}$ Andrew Campbell, PhD, \\ Alisa Joy Wiskin, MS, ${ }^{3}$ Paul Miki L. Seng Du, MEd, ${ }^{4}$ Theh Mar, MS, ${ }^{4}$ and Andy Nilsen, BComm ${ }^{3}$
}

\begin{abstract}
Since Myanmar's transition to civilian rule in 2011, the use of smartphones has exploded. The ubiquitous use of social media, in particular Facebook, has had a well-publicized dark side as a platform for disseminating fake news and hate speech. With poor digital literacy skills, Myanmar users are susceptible to disinformation campaigns and other online dangers, particularly young people, the most prevalent users. The current study collected benchmarking data related to usage patterns and perceptions of social media among Myanmar youth living in conflict-affected areas, including internally displaced Rohingya Muslims whose voice is yet to be captured in social media research. A total of 231 participants from Rakhine and Kayah States aged 13-35 were surveyed about their use of social media and its impact on Myanmar society and their own lives. More than half of the young people sampled were heavy smartphone users, particularly Rohingya Muslims, who rely on social media for contact with society outside of their camps. Facebook was by far the most used app, however, private group chat-based platforms were also popular. A majority said that they check the accuracy of news they read on social media, however, most do so by checking other Facebook pages or asking friends or family. Overall, most young people thought that social media has both a positive impact and negative impact on their lives. This study adds to an emerging body of research into how Myanmar youth engage with social media, particularly regarding how they consume news of current events.
\end{abstract}

Keywords: social media, Facebook, hate speech, fake news, Myanmar, Rohingya

Introduction

$\mathbf{F}$ Ollowing MyanmaR's TRANSITION from military to civilian rule in 2011, the introduction of affordable, webenabled mobile communication devices has transformed how its population consumes information and mobilizes social movements. ${ }^{1,2}$ While bringing practical and social benefits, the ubiquitous use of social media in Myanmar has had a well-publicized dark side-enabling the rapid distribution of fake news and hate speech that has played a role in inciting intercommunal conflict as far back as 2012.,4

Facebook is the most widely used social media platform in Myanmar (20-25 million monthly active users, ${ }^{5}$ almost $50 \%$ of the population). However, many Myanmar users are not using Facebook for social networking, but as a search engine and to read news. 6 The popular idea that "Facebook is the Internet" is so often repeated in relation to Myanmar online use, it is clichéd. ${ }^{7}$ According to a Telenor report, ${ }^{8} 78 \%$ of Myanmar Internet users have poor digital literacy skills due to their lack of previous experience with digital media. Without the tools needed to navigate the online world safely, responsibly, and critically, Myanmar users are thought to be especially susceptible to disinformation campaigns. As such, one of the most obvious issues with Facebook's sudden spread across Myanmar is the creation and dissemination of fake news and hate speech. ${ }^{3}$ This has been identified as playing a major role in inciting violence against Rohingya living in the Rakhine State, ${ }^{9,10}$ who according to Thawnghmung $^{11}$ are viewed by many Myanmar Buddhists as illegal residents because they are Muslims and have darker skin. As of March 2019, over 909,000 Rohingya have been forced to flee Myanmar, ${ }^{12}$ and those who remain are confined to isolated villages and internally displaced persons (IDP) camps with their access to education, health care, and freedom of movement greatly curtailed.

Young people aged 13-35 years are the most prevalent users of social media in Myanmar, ${ }^{13}$ and so are particularly at risk from any of its potential negative effects. However,

\footnotetext{
${ }^{1}$ Cyberpsychology Research Group, Faculty of Medicine and Health, The University of Sydney, Sydney, Australia.

${ }^{2}$ School of Anthropology \& Museum Ethnography, University of Oxford, Oxford, United Kingdom.

${ }^{3}$ Save The Children International, Yangon, Myanmar.

${ }^{4}$ Independent Consultant, Yangon, Myanmar.
} 
Table 1. Demographics

\begin{tabular}{|c|c|c|c|c|c|c|c|c|c|c|c|}
\hline Subsample & Overall & Male & Female & $\begin{array}{l}\text { Kayah } \\
\text { State }\end{array}$ & $\begin{array}{l}\text { Rakhine } \\
\text { State }\end{array}$ & $\begin{array}{l}\text { Kayah } \\
\text { Urban }\end{array}$ & $\begin{array}{l}\text { Kayah } \\
\text { Rural }\end{array}$ & $\begin{array}{l}\text { Rakhine } \\
\text { Urban }\end{array}$ & $\begin{array}{c}\text { Muslim } \\
\text { IDP }\end{array}$ & Rural & Urban \\
\hline $\begin{array}{l}N \\
\text { Gender }\end{array}$ & 232 & 110 & 113 & 106 & 125 & 68 & 38 & 64 & 61 & 38 & 132 \\
\hline Male & $\begin{array}{c}110 \\
(47.6 \%)\end{array}$ & & & $\begin{array}{c}40 \\
(37.7 \%)\end{array}$ & $\begin{array}{c}70 \\
(56.0 \%)\end{array}$ & $\begin{array}{c}22 \\
(32.4 \%)\end{array}$ & $\begin{array}{c}18 \\
(47.4 \%)\end{array}$ & $\begin{array}{c}31 \\
(48.4 \%)\end{array}$ & $\begin{array}{c}39 \\
(63.9 \%)\end{array}$ & $\begin{array}{c}18 \\
(47.4 \%)\end{array}$ & $\begin{array}{c}53 \\
(48.2 \%)\end{array}$ \\
\hline Female & $\begin{array}{c}113 \\
(48.9 \%)\end{array}$ & & & $\begin{array}{c}61 \\
(54.0 \%)\end{array}$ & $\begin{array}{c}52 \\
(41.6 \%)\end{array}$ & $\begin{array}{c}44 \\
(64.7 \%)\end{array}$ & $\begin{array}{c}17 \\
(44.7 \%)\end{array}$ & $\begin{array}{c}32 \\
(50.0 \%)\end{array}$ & $\begin{array}{c}20 \\
(32.8 \%)\end{array}$ & $\begin{array}{c}17 \\
(44.7 \%)\end{array}$ & $\begin{array}{c}76 \\
(67.3 \%)\end{array}$ \\
\hline $\begin{array}{l}\text { Other } \\
\text { responses }\end{array}$ & $\begin{array}{c}8 \\
(3.5 \%)\end{array}$ & & & $\begin{array}{c}5 \\
(4.7 \%)\end{array}$ & $\begin{array}{c}3 \\
(2.4 \%)\end{array}$ & $\begin{array}{c}2 \\
(2.9 \%)\end{array}$ & $\begin{array}{c}3 \\
(7.9 \%)\end{array}$ & $\begin{array}{c}1 \\
(1.6 \%)\end{array}$ & $\begin{array}{c}2 \\
(3.3 \%)\end{array}$ & $\begin{array}{c}3 \\
(7.9 \%)\end{array}$ & $\begin{array}{c}3 \\
(2.3 \%)\end{array}$ \\
\hline Mean age & $\begin{array}{l}21.84 \\
(3.94)\end{array}$ & $\begin{array}{l}21.75 \\
(3.51)\end{array}$ & $\begin{array}{l}21.78 \\
(4.19)\end{array}$ & $\begin{array}{l}21.50 \\
(4.44)\end{array}$ & $\begin{array}{l}22.14 \\
(3.46)\end{array}$ & $\begin{array}{l}21.04 \\
(4.67)\end{array}$ & $\begin{array}{l}22.32 \\
(3.93)\end{array}$ & $\begin{array}{l}23.08 \\
(3.66)\end{array}$ & $\begin{array}{l}21.15 \\
(2.94)\end{array}$ & $\begin{array}{l}22.32 \\
(3.93)\end{array}$ & $\begin{array}{l}22.03 \\
(4.32)\end{array}$ \\
\hline
\end{tabular}

IDP, internally displaced persons.

very little substantive research has investigated how young people in conflicted-affected areas of Myanmar actually use social media, particularly in relation to their trust in the news they consume on these platforms.

As such, there is a clear need for benchmarking data related to current usage patterns and perceptions of social media among youth, particularly those in conflict-affected areas, including Rohingya Muslims whose voice is yet to be captured in social media research. The current study therefore aimed to answer the following research questions: (a) Which social media apps are most popular among young people in conflict-affected areas of Myanmar, and how are they primarily used and (b) do young people in conflictedaffected areas of Myanmar consume news on social media, and if so do they trust this information and/or check its accuracy?

\section{Methods}

As part of a larger mixed-methods study, a paper-based survey was administered in Myanmar language to 121 participants recruited for focus groups. A further convenience sample of 135 participants were recruited from public spaces in Kayah and Rakhine States. Twenty-four participants outside the target age range for the study (13-35 years) were excluded. The sample for analysis was therefore 231, with 106 responses from Kayah State (38 rural, 68 urban) and 125 from Rakhine State (61 IDP, 64 urban). The IDP subsample included a small unknown number of Kaman Muslims in addition to Rohingya Muslims, and so is referred to in this report as 'Muslim IDP'. The gender split of the overall sample was even (Table 1) and the mean overall age was 21.84 years $(S D=3.94$, range $14-35$ years $)$.

The survey was designed by M.M. in consultation with A.W. and B.R. It asked participants a range of check-box and Likert-type scale items about their social media use, experiences consuming news via social media, and the impact of social media on Myanmar society and their own lives. Ethics approval for the survey was gained from the Ethics Review Committee of Save the Children US.

\section{Results}

Full results of the survey by gender and state subsamples are available in Appendix Table A1.

\section{General use}

Just over half of the sample reported spending 1-5 hours a day on their phone $(53.0 \%)$, and $17.0 \%$ spent more than 5 hours a day (Fig. 1). When responses were converted to an ordinal 1-6-point scale, Kruskal-Wallis tests revealed that on average the Rakhine State subsample used their phone significantly more than the Kayah State subsample $(H(1)=16.25, p<0.001 ; \eta 2=0.07$, a moderate effect size $)$ and IDP respondents significantly more than urban or rural respondents $(H(2)=9.58 ; p<0.01 ; \eta 2=0.03$, a small effect

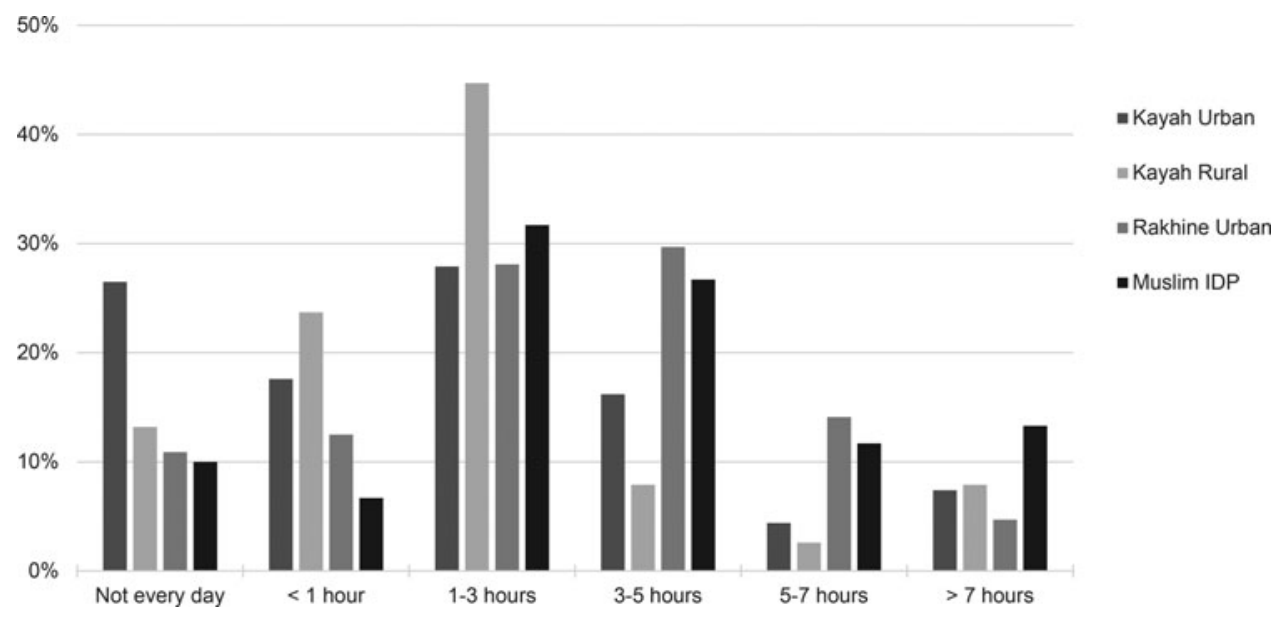

FIG. 1. Average daily mobile phone use. IDP, internally displaced persons. 


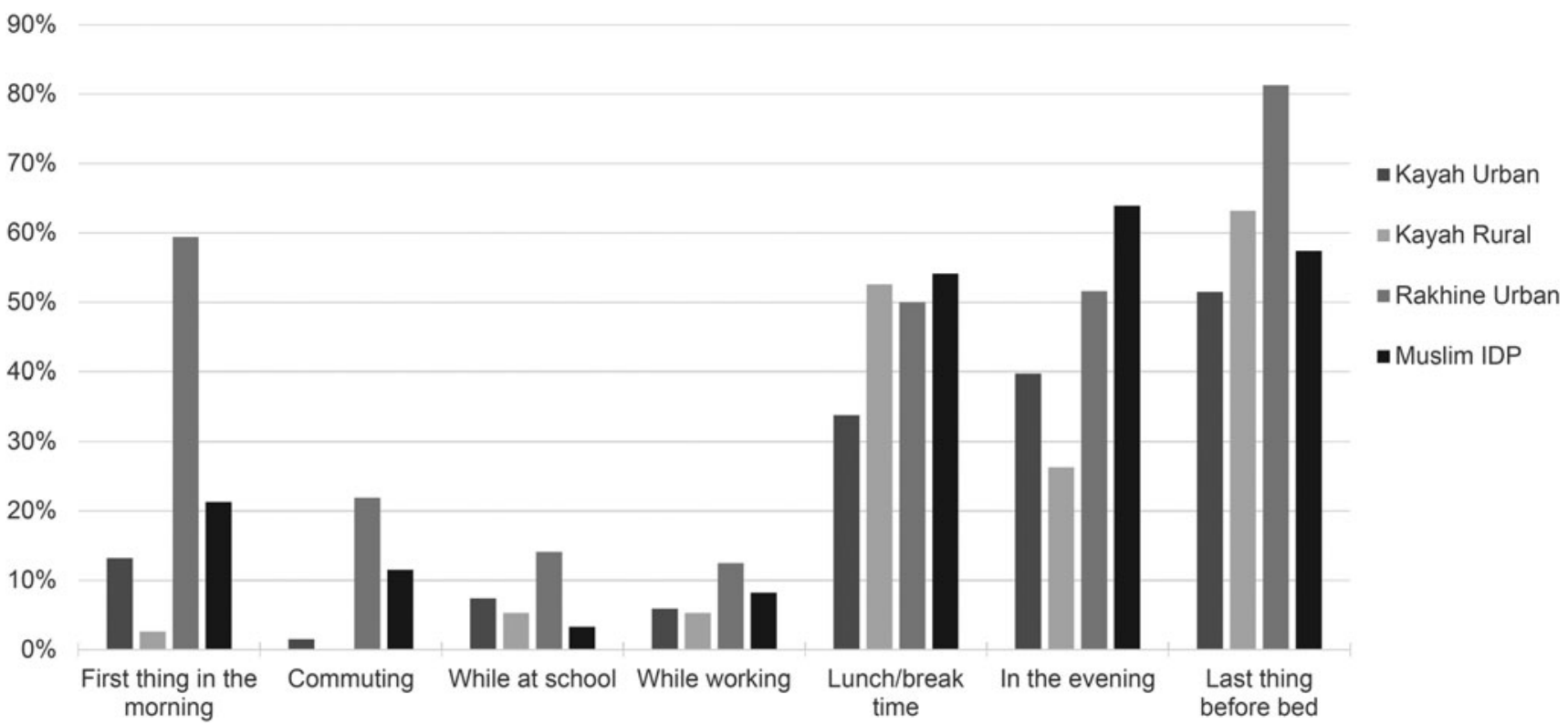

FIG. 2. When do you use social media?

size). Overall, the most common times for using social media were last thing before bed (63.4\%), evening (47.0\%), and lunch/break time (46.6\%) (Fig. 2). Most respondents thought they spent "the right amount of time" on social media (59.7\%), with only $10.6 \%$ thinking that they spent too much time (and 20.8\% thinking they did not spend enough time).

\section{Social media apps and activity}

Facebook and its sister app, Messenger, were by far the most frequently used apps among all demographics (identified by $87.4 \%$ and $71.4 \%$, respectively, overall), followed by Viber (30.3\%) (Fig. 3). IDP respondents were also frequent users of group chat-based apps IMO (72.1\%) and WeChat
(55.7\%). YouTube was not listed among the choices, as many do not consider it a social media app per se. It was identified using the "other" option by $7.4 \%$ of the overall sample, but focus group discussions indicated that the overall use among Myanmar young people is likely much higher than this. ${ }^{14}$

The most common ways to interact on social media included sharing news and information (66.4\%), sharing health tips (48.3\%), posting selfies (43.5\%), posting reactions and/ or emojis (39.7\%), and sharing news about educational opportunities (39.2\%). There were large gender differentials for sharing news (76.4\% of males vs. $56.6 \%$ of females) and posting selfies (53.6\% vs. $36.3 \%)$. Rural respondents were less likely to share news about education, or post selfies, reactions/emojis, or about their life (Fig. 4).

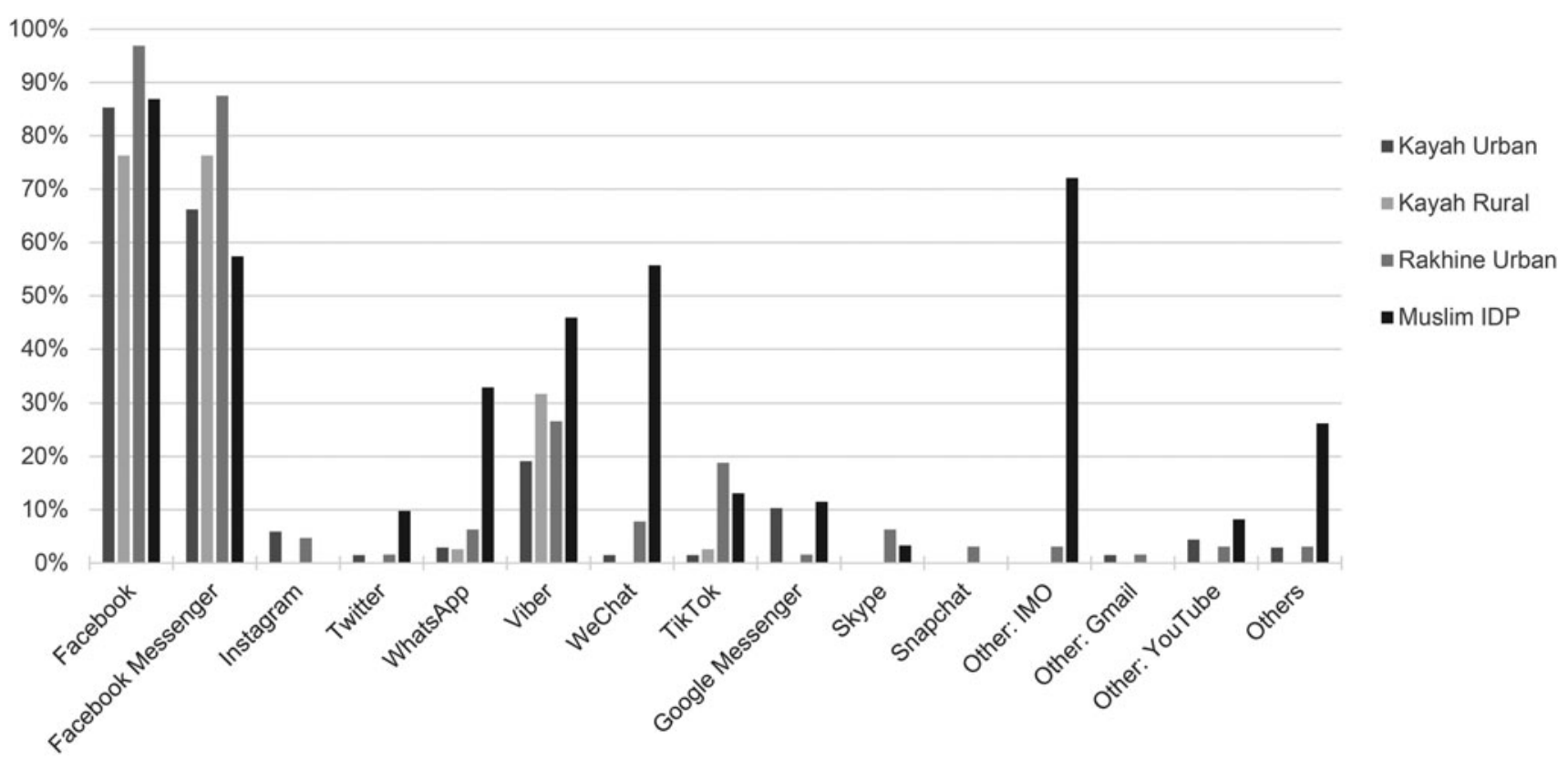

FIG. 3. Most frequently used social media apps. 


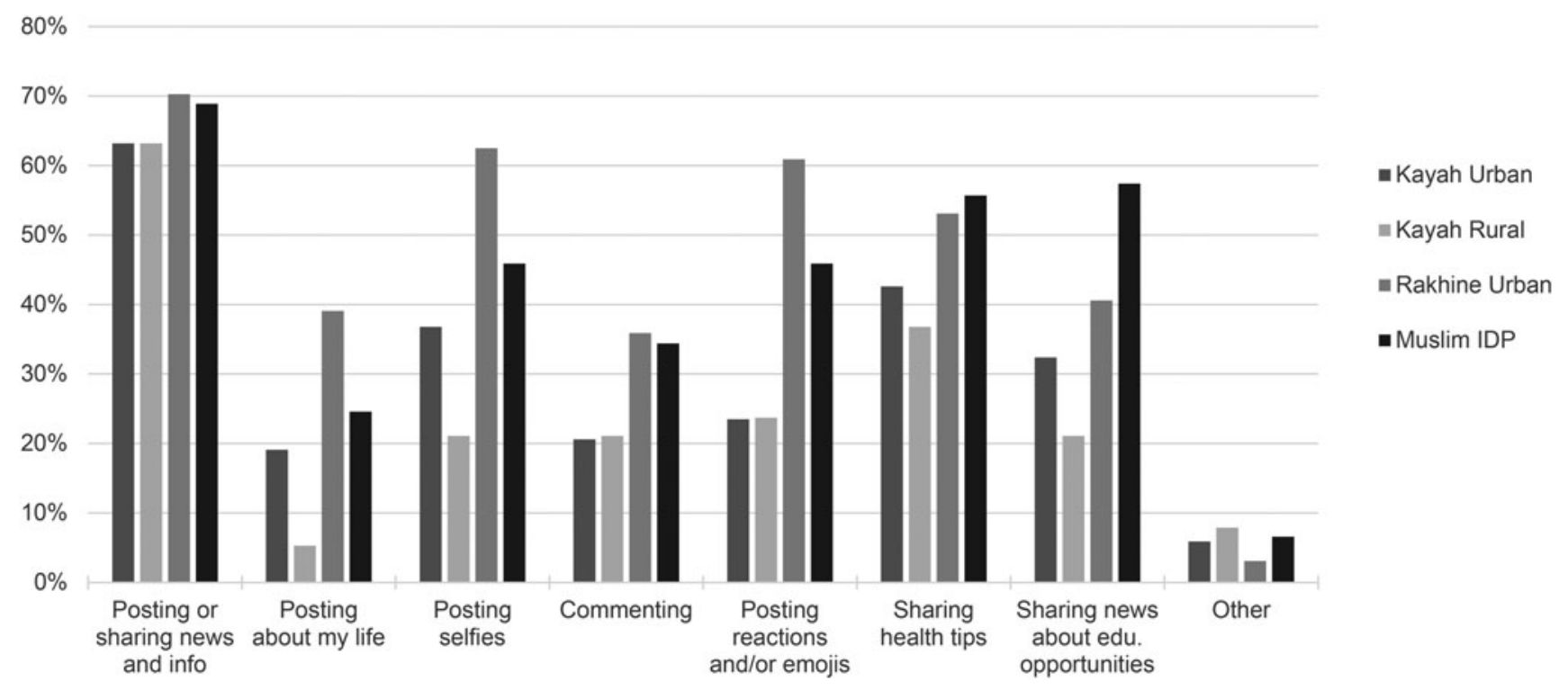

FIG. 4. Most common ways to interact on social media.

\section{News on social media}

Overall, $58.0 \%$ of respondents indicated they use social media, predominantly Facebook, to read news (Fig. 5). IDP respondents were significantly more likely to use social media to read news $(84.5 \%)$ compared with rural $(42.9 \%)$ and urban respondents $(49.6 \%)$.

Just over half of the overall sample indicated they get the same amount of news from social media and traditional media (53.4\%). Around one-third of the overall sample (34.2\%) indicated that they get more news from social media apps compared with traditional media, with the proportion highest for IDP respondents (45.3\%). More rural respondents reported getting most of their news from traditional media $(31.0 \%)$, compared with IDP (13.2\%) and urban respondents (7.2\%).

When asked if they trust news seen on social media, the most common response was "sometimes" (42.2\%), followed by often/usually (33.2\%) (Fig. 6). When responses were converted to an ordinal 1-5-point scale, KruskalWallis tests revealed that on average, IDP respondents had a significantly higher level of trust in news on social media compared with the urban and rural respondents $(H(2)=$ 25.46, $p<0.001 ; \eta 2=0.10$, a moderate effect size), and males a significantly higher level of trust compared with females $(H(1)=5.39 ;, p<0.05 ; \eta 2=0.02$, a small effect size).

Most of the overall sample indicated they check the accuracy of news read on social media $(65.1 \%)$, with rates highest among the IDP (89.5\%) and male (77.4\%) subsamples. The most common methods were asking friends or family (60.4\%), checking other Facebook pages (59.7\%), and checking other news sources (50.0\%) (Fig. 7).

\section{Impacts of social media}

Overall, most respondents thought social media has both a positive and negative impact on their lives (66.7\%). IDP

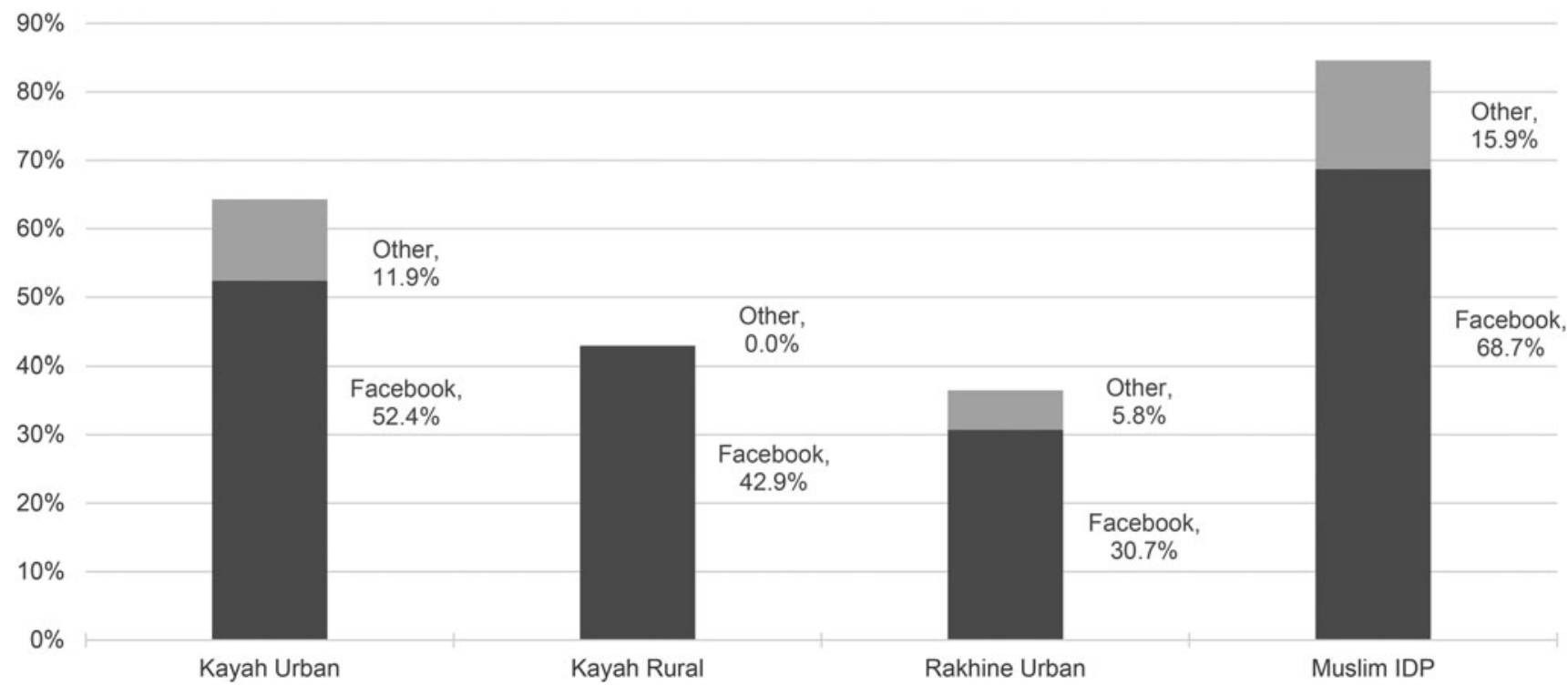

FIG. 5. Social media platform used to read news. 
$70 \%$

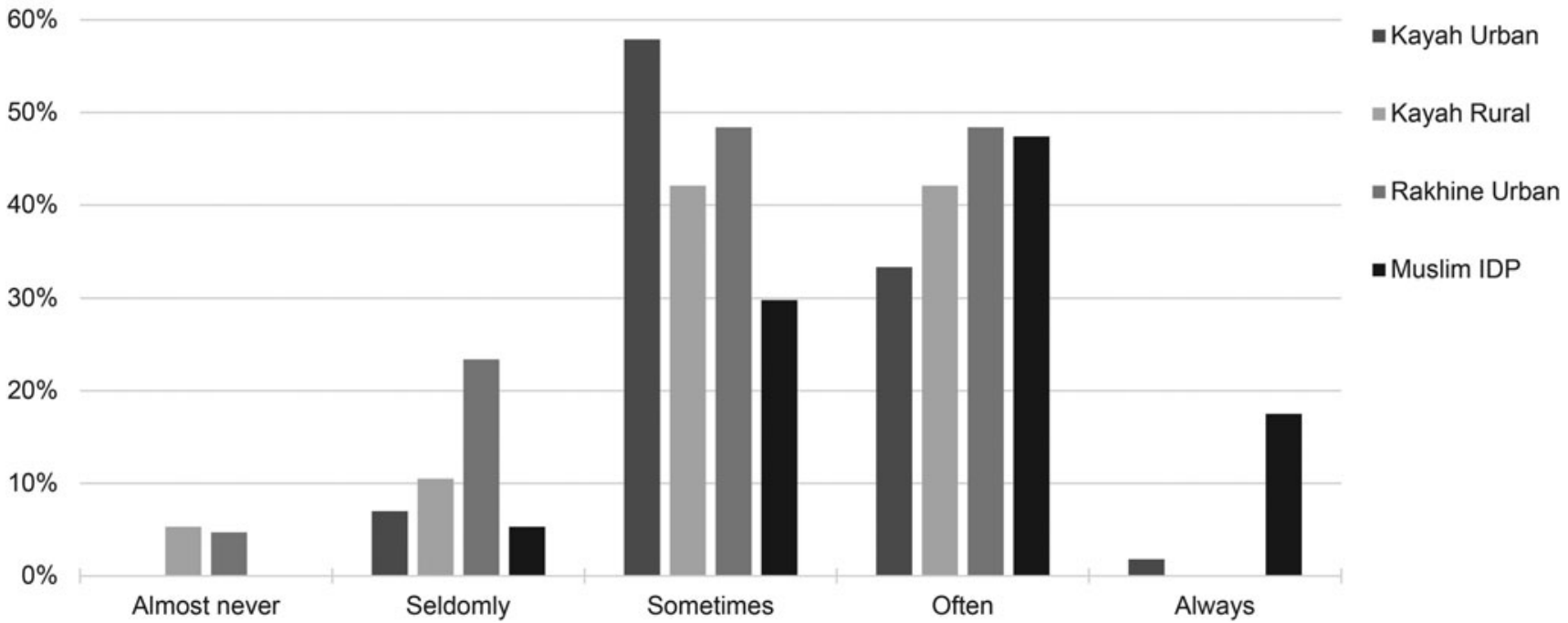

FIG. 6. How often to trust news from social media.

respondents were much more likely to think that social media has a mostly positive impact on their lives (Fig. 8).

Most respondents thought that social media has both a positive and negative impact on Myanmar society (72.2\%), with $22.7 \%$ thinking it a mostly positive impact, and only $4.7 \%$ a mostly negative impact. Location and state differentials were similar to the previous question (Fig. 9).

\section{Discussion}

The results of this study confirm that smartphone and social media use among young people in Myanmar is high compared with other developing countries in Africa, the Middle East, and parts of South America, as it rapidly approaches the level of countries in the Organisation for Eco- nomic Cooperation and Development (OECD). ${ }^{15}$ In the United States, more than half of teens report spending too much time on their phones, ${ }^{16}$ yet only $10 \%$ of Myanmar youth in the current study said this, with $20 \%$ actually saying they do not spend enough time on their phones, such is the normalization of heavy phone use among their peers. Many young people in Myanmar reported using use their phones whenever they are not working or studying, distracting from other more active tasks and keeping them up late at night. ${ }^{14}$ Similar heavy use patterns across the span of the day have been observed in OECD countries ${ }^{13}$ where parents are concerned about the potential impact of screen time on their children's sleep, mental health, and physical activity. Qualitative analyses conducted in the larger mixed-method study that the current results are part of revealed that parents in

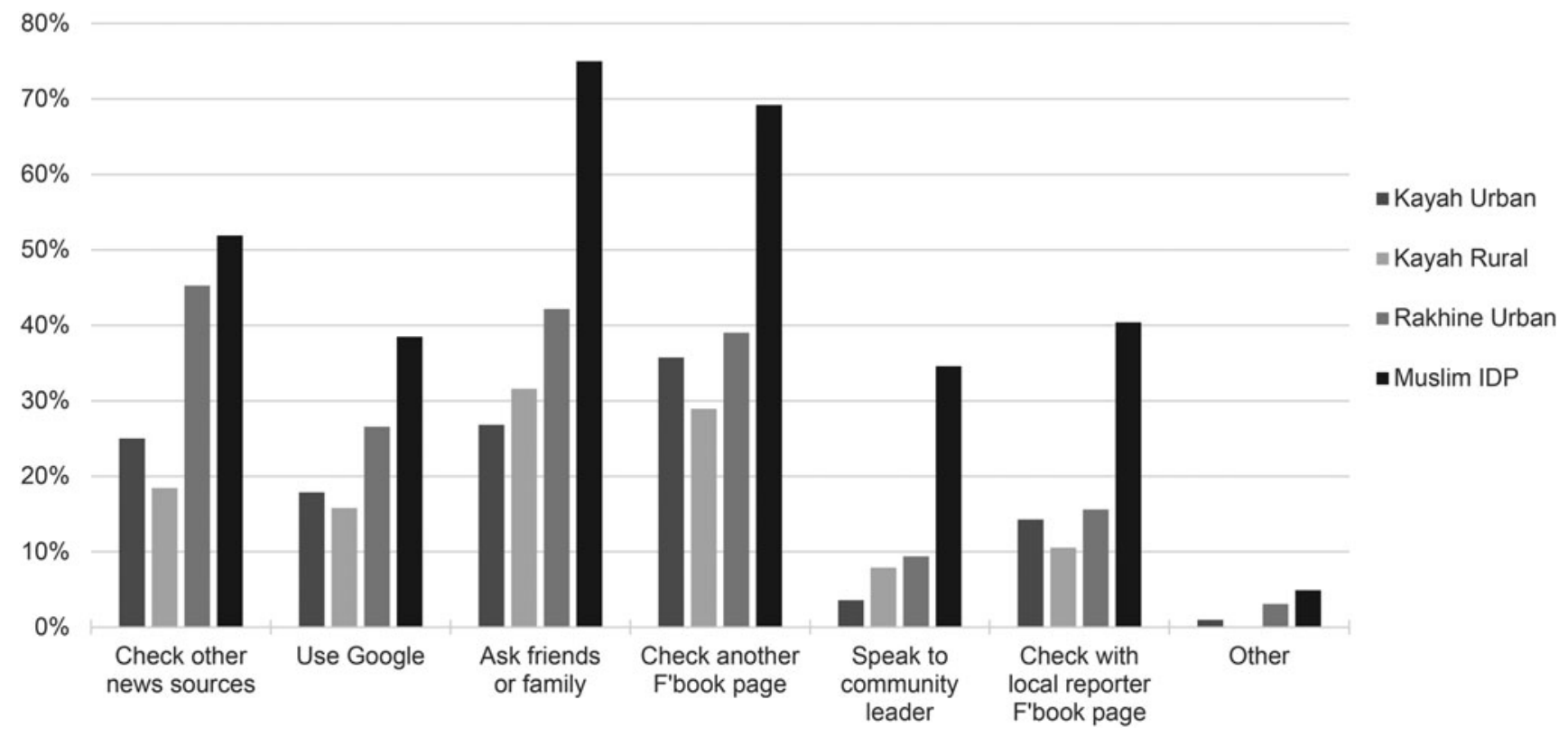

FIG. 7. Checking accuracy of news on social media. 


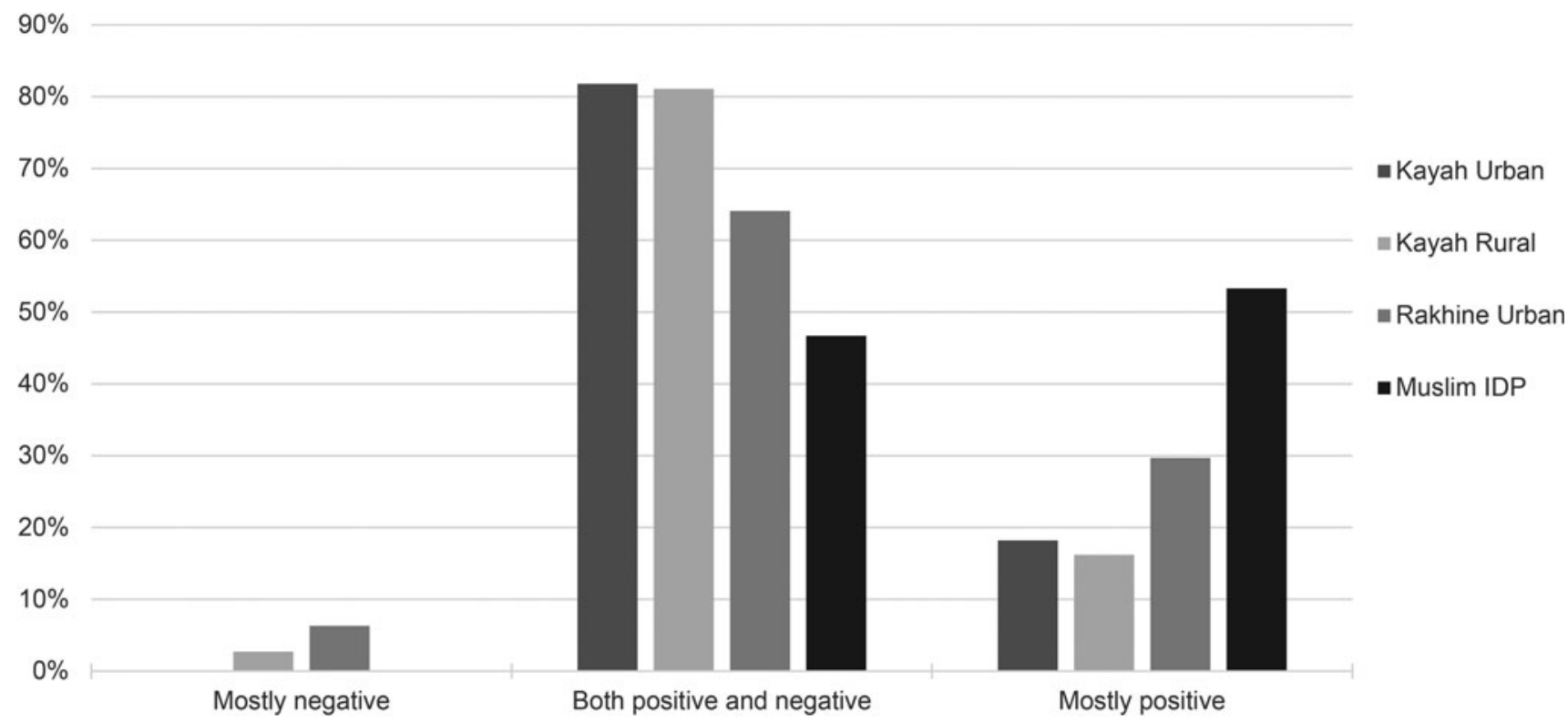

FIG. 8. Impact of social media on own life.

Myanmar are also worried about how long their children spend on their phones, however, their concerns are mostly around the impact on their studies. ${ }^{14}$

Muslim IDP participants were the heaviest users of social media, likely due to current restrictions on their movement, lack of education and vocational opportunities, and reliance on social media for contact outside of their IDP camps. Rural participants in Kayah State were the lightest users, likely due to their longer work hours, lower disposal income to pay for phone credit, and poorer network connectivity.

Facebook was the most popular platform among young people in Rakhine and Kayah States, consistent with previous studies in Myanmar. ${ }^{7,17,18}$ Notable exceptions were preference for closed chat-based platforms such as Viber and WeChat ${ }^{14}$ among young Muslim girls living in IDP camps (who were restricted in their use of Facebook by religious and cultural norms), and some girls from rural Kayah villages. While the widespread use of group chat-based platforms in Muslim IDP communities has been identified previously, ${ }^{19}$ the popularity of IMO, which has similar functionality but a much larger group size limit (up to 100,000), is documented for the first time in the current study. These results challenge the idea that "Facebook is the Internet," $"$ with evidence that young people in conflictaffected areas using other social media platforms perceived as more private and with functionality that Facebook lacks.

Sharing news and information was the most common reason for using social media. Interestingly, almost half of all respondents also reported that they share health tips online. The sharing of news about educational opportunities was

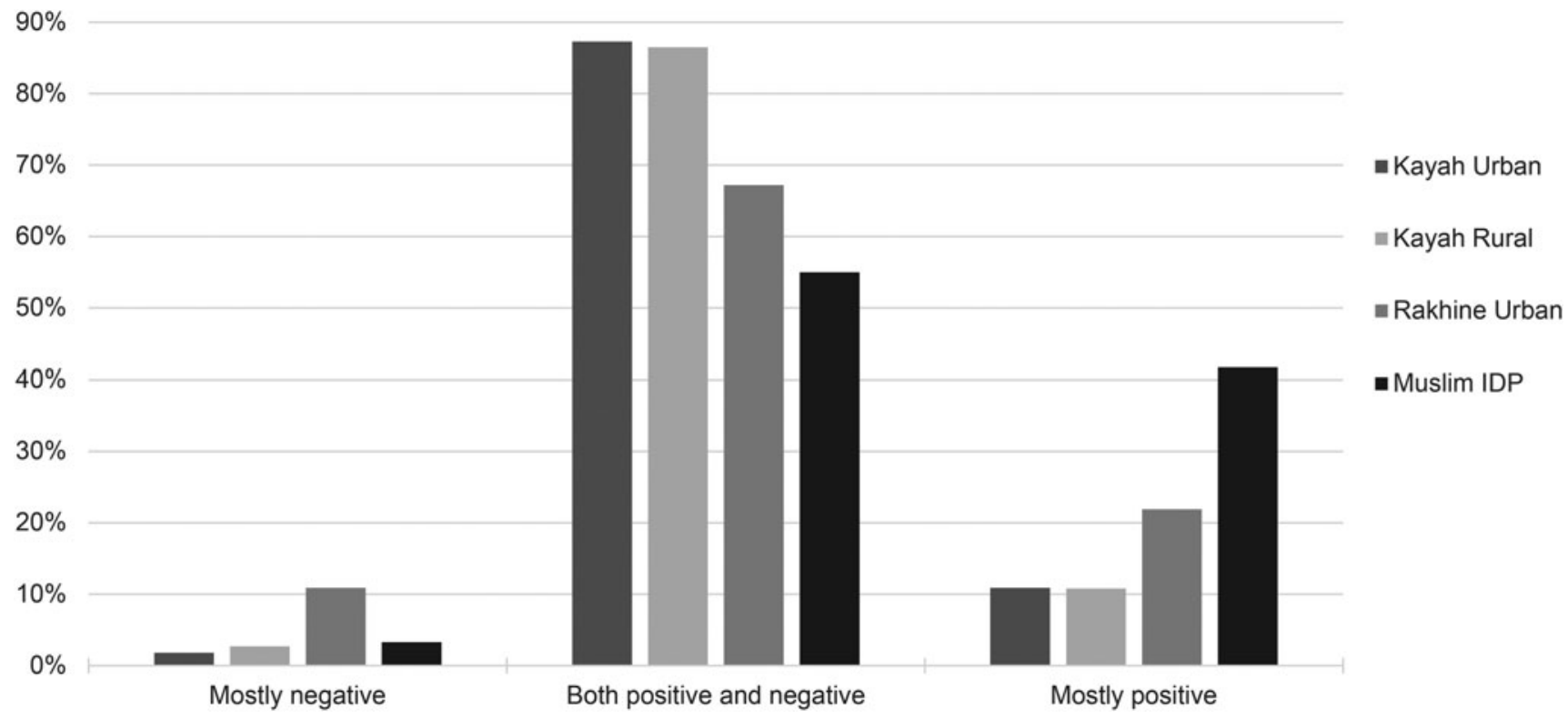

FIG. 9. Impact of social media on Myanmar. 
also popular. The identification of these as primary activities differs to those typically identified by young people from OECD countries, who engage in more online gaming, general chat, and original photo and video sharing, particularly via Snapchat and Instagram (which have risen in popularity among young people at the expense of Facebook in recent years $^{20}$ ). In the current study, Instagram was only widely used by youth living in urban Rakhine, with Snapchat use virtually nonexistent. Playing games and posting selfies were popular among boys, but less popular among Myanmar girls who are advised not to post pictures of themselves to prevent image-based abuse. ${ }^{14}$ Another interesting finding was that rural youth were less likely to post about their own lives compared with those in urban areas.

Most respondents said they get news about current events from social media (predominantly Facebook), with around a third stating that social media was their primary source of news. This is consistent with the worldwide average across countries with emerging and developed economies. ${ }^{21}$ Rural participants reported getting more of their news from traditional media than urban participants, while Muslim IDP participants reported the heaviest reliance on social media for their news.

Most young people said that they check the accuracy of news they read on social media. However, Meers suggested that "people are not always as diligent as they say they are in the way that they check the information they receive". ${ }^{22(p 4)}$ While there is no way to determine how accurate self-reports of checking behavior are, there was a general perception among young people that their peers' trust in news on social media is low, and that it is adults who most actively share fake news without checking it for accuracy. ${ }^{14}$ In contrast, many adults in the qualitative interviews blamed the spread of fake news on a lack of critical thinking skills among young users. Interestingly, a recent study into fake news regarding the 2016 U.S. election campaign found that the likelihood of sharing fake news stories increased with age, ${ }^{23}$ although it should be noted that no participants younger than 30 years were included in that study. Other studies conducted in Myanmar have found that new users are less critical than those who have been online longer, suggesting age is less significant a factor than experience. 7,14

More research is needed into the mechanisms behind the spread of fake news both in Myanmar and internationally, but it is likely to be primarily related to low digital and media literacy rather than age per se, which would explain the differing views between generations in Myanmar. The results of the larger mixed-method study support this hypothesis, with young people saying that they have become less susceptible to believing fake news (and less trusting of news overall) with more experience on social media, and it is users who are new to social media who are most likely to believe fake news. ${ }^{14}$

The most common ways of checking the validity of news were to ask friends and family or check another Facebook page. Using Google was identified by only $34 \%$ of survey respondents. Many young people in Myanmar consider Google "harder to use" than Facebook, ${ }^{14}$ as it cannot properly reconcile Myanmar's Zawgyi font encoding (which is not Unicode compliant). This overreliance on Facebook is problematic, given the proliferation of fake news on the platform and that $78 \%$ of Myanmar Internet users have poor digital literacy skills. ${ }^{8}$
Overall, most young people thought social media has both a positive impact and negative impact on their lives and Myanmar society. Muslim IDP were more likely to think social media has a mostly positive impact, reflecting its importance for connecting them to society outside their camp. This is despite issues Muslim IDP regularly encounter such as hate speech and harassment, which are discussed in detail in the larger mixed-method study report. ${ }^{14}$

\section{Limitations}

There were sampling and time limitations that resulted in inconsistent age and gender distributions between subsamples in this study. There may have also been selection bias, in that young people who volunteered for the study may have had above average interest in social media, and thus bias responses toward those of heavy and/or more knowledgeable users. Finally, as comparisons made in this study are based on ordinal data and hence necessitated nonparametric analyses, results do not assume a normal distribution and should therefore be interpreted with caution.

\section{Conclusion}

Although it has been clear for a number of years that digital connectedness has played an important role in the lives of young people in Myanmar, research in this area has been limited. This study represents an important addition to the emerging body of research into how Myanmar youth engage with social media, particularly regarding how they consume news of current events. These results suggest that young people living in conflict-affected areas of Myanmar are aware of the proliferation of fake news on social media, and often check the accuracy of the news they receive from this medium. However, the overreliance on Facebook for checking news accuracy, combined with poor digital literacy skills and low levels of trust in traditional and state-run media, may have a negative impact on the information ecosystem within which young people in Myanmar exist.

\section{Author Disclosure Statement}

No competing financial interests exist.

\section{Funding Information}

This study was funded by Save The Children International.

\section{References}

1. McCarthy G. (2017) Cyber-spaces. In Simpson A, Farrelly N, Holliday I, eds. Routledge handbook of contemporary Myanmar. London, United Kingdom: Routledge, pp. 92-105.

2. Min TT, Fife E, Bohlin E. (2014) Consumer demand for the mobile Internet in a greenfield emerging market: the case of Myanmar. Paper presented at the 20th International Telecommunications Society Biennial Conference, Rio de Janeiro, Brazil, November 30-December 3.

3. Fink C. Dangerous speech, anti-muslim violence, and Facebook in Myanmar. Journal of International Affairs 2018; 71:43-52.

4. Mozur P. (2018) A genocide incited on Facebook, with posts from Myanmar's military. https://www.nytimes.com/ 
2018/10/15/technology/myanmar-facebook-genocide.html (accessed Sep. 16, 2019).

5. Facebook. (2019) Audience insight. https://www.facebook .com/ads/audience-insights/people $?$ act $=28036637 \&$ age $=18$ \&country=MM (accessed Sep. 16, 2019).

6. Silverman C. (2018) Can positive messaging on social media promote peacebuilding in Myanmar? http://muep .mau.se/handle/2043/25017 (accessed Sep. 16, 2019).

7. Oo TS, Thant, YM. (2019) Exploring digital and mobile cultures in Myanmar 2019. https://www.digitalculturesmm .com/ (accessed Sep. 16, 2019).

8. Telenor. (2018) Realising digital Myanmar: leapfrogging to an inclusive digital economy. https://www.telenor.com/wpcontent/uploads/2018/02/Telenor-Realising-Digital-MyanmarReport-06-February.pdf (accessed Sep. 16, 2019).

9. McKirdy E. (2018) When Facebook becomes 'the beast': Myanmar activists say social media aids genocide. https:// edition.cnn.com/2018/04/06/asia/myanmar-facebook-socialmedia-genocide-intl/index.html (accessed Sep. 16, 2019).

10. Lee R. Extreme speech in Myanmar: the role of state media in the Rohingya forced migration crisis. International Journal of Communication 2019; 13:22.

11. Thawnghmung AM. The politics of indigeneity in Myanmar: competing narratives in Rakhine state. Asian Ethnicity 2016; 17:527-547.

12. United Nations Office for the Coordination of Humanitarian Affairs. (2020) Rohingya refugee crisis. https:// www.unocha.org/rohingya-refugee-crisis (accessed Sep. 16, 2019).

13. Graafland JH. (2019) New technologies and 21st century children: recent trends and outcomes. https://www.oecdilibrary.org/education/new-technologies-and-21st-centurychildren_e071a505-en (accessed Sep. 16, 2019).

14. Ridout B, McKay M, Amon K, et al. (2019) Impact of social media on youth living in conflict-affected regions of Myanmar. London, United Kingdom: The University of Sydney \& Save The Children International.

15. Poushter J, Bishop C, Chwe J. (2018) Social media use continues to rise in developing countries but plateaus across developed ones. https://www.pewresearch.org/global/2018/ 06/19/3-social-network-adoption-varies-widely-by-country/ (accessed Sep. 16, 2019).

16. Anderson M, Jiang J. (2018) Teens, Social Media and Technology 2018. https://www.pewinternet.org/wp-con tent/uploads/sites/9/2018/05/PI_2018.05.31_TeensTech_ FINAL.pdf (accessed Sep. 16, 2019).

17. McKay M. (2017) Research into Myanmar Facebook use (Unpublished report). Yangon, Myanmar: Phandeeyar.

18. Grizelj I. (2017) The youth space of dialogue and mediation in Myanmar. https://www.berghof-foundation.org/file admin/redaktion/Publications/Other_Resources/YouthSpace ofDialogueMediation_Myanmar.pdf (accessed Sep. 16, 2019).

19. Thu JM. (2016) Rakhine State news and information ecosystem: An Internews rapid assessment report. Yangon, Myanmar: Internews.

20. Martin F, Wang C, Petty T, et al. Middle school students' social media use. Journal of Educational Technology \& Society 2018; 21:213-224.

21. Smith A, Anderson M. (2018) Social media use in 2018. https://www.pewinternet.org/2018/03/01/social-media-usein-2018/ (accessed Sep. 16, 2019).

22. Meers ES. (2015) Community information flows to reduce inter-communal violence in Burma. https://www.sfcg.org/ wp-content/uploads/2016/09/Myanmar-Community-Informa tion-Management-Report.-SFCG.-March-2016.pdf (accessed Sep. 16, 2019).

23. Guess A, Nagler J, Tucker J. Less than you think: prevalence and predictors of fake news dissemination on Facebook. Science Advances 2019; 5:eaau4586.

Address correspondence to:

Dr. Brad Ridout

Cyberpsychology Research Group

Faculty of Medicine and Health

The University of Sydney

Sydney 2006

Australia

E-mail: brad.ridout@sydney.edu.au 


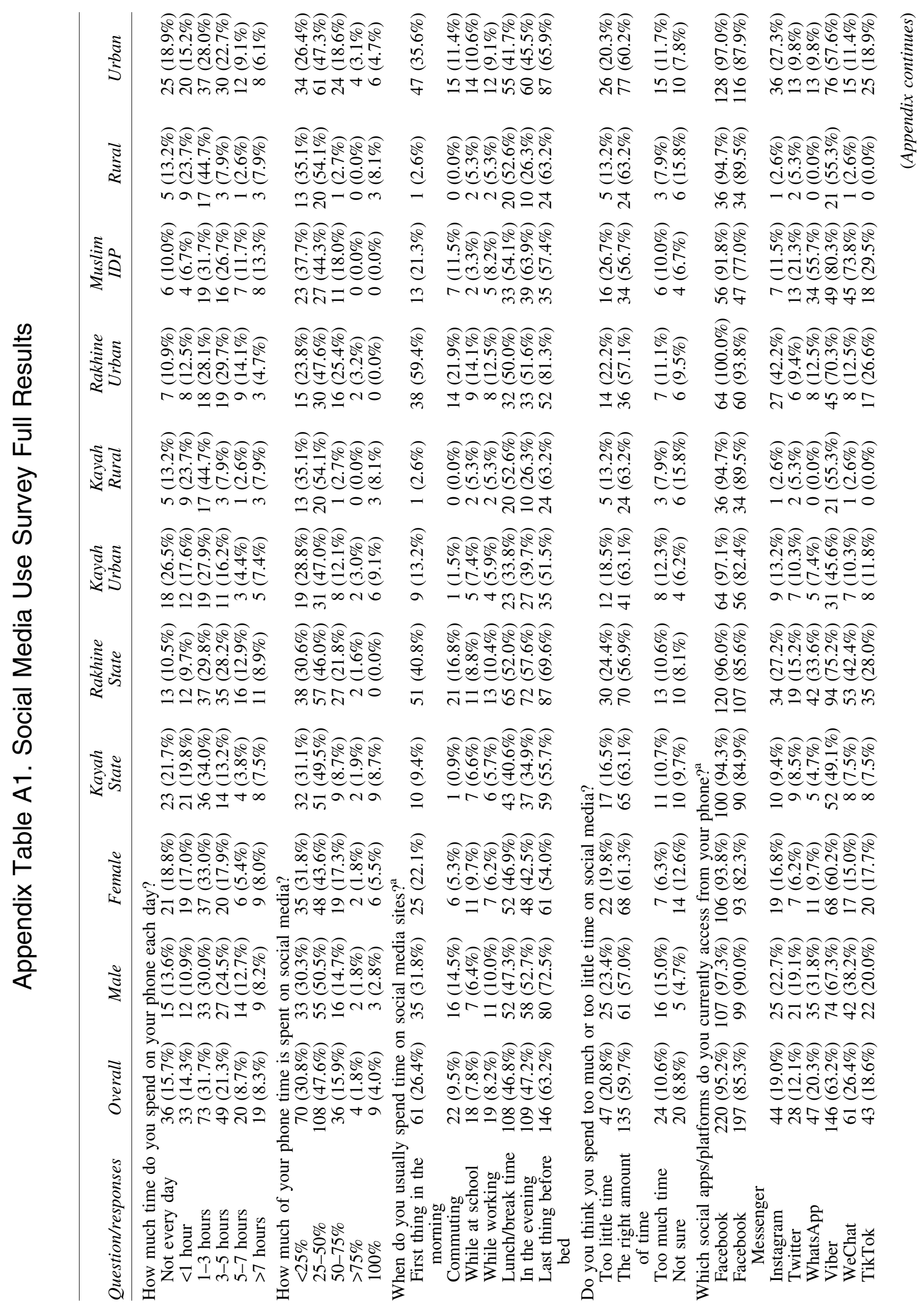




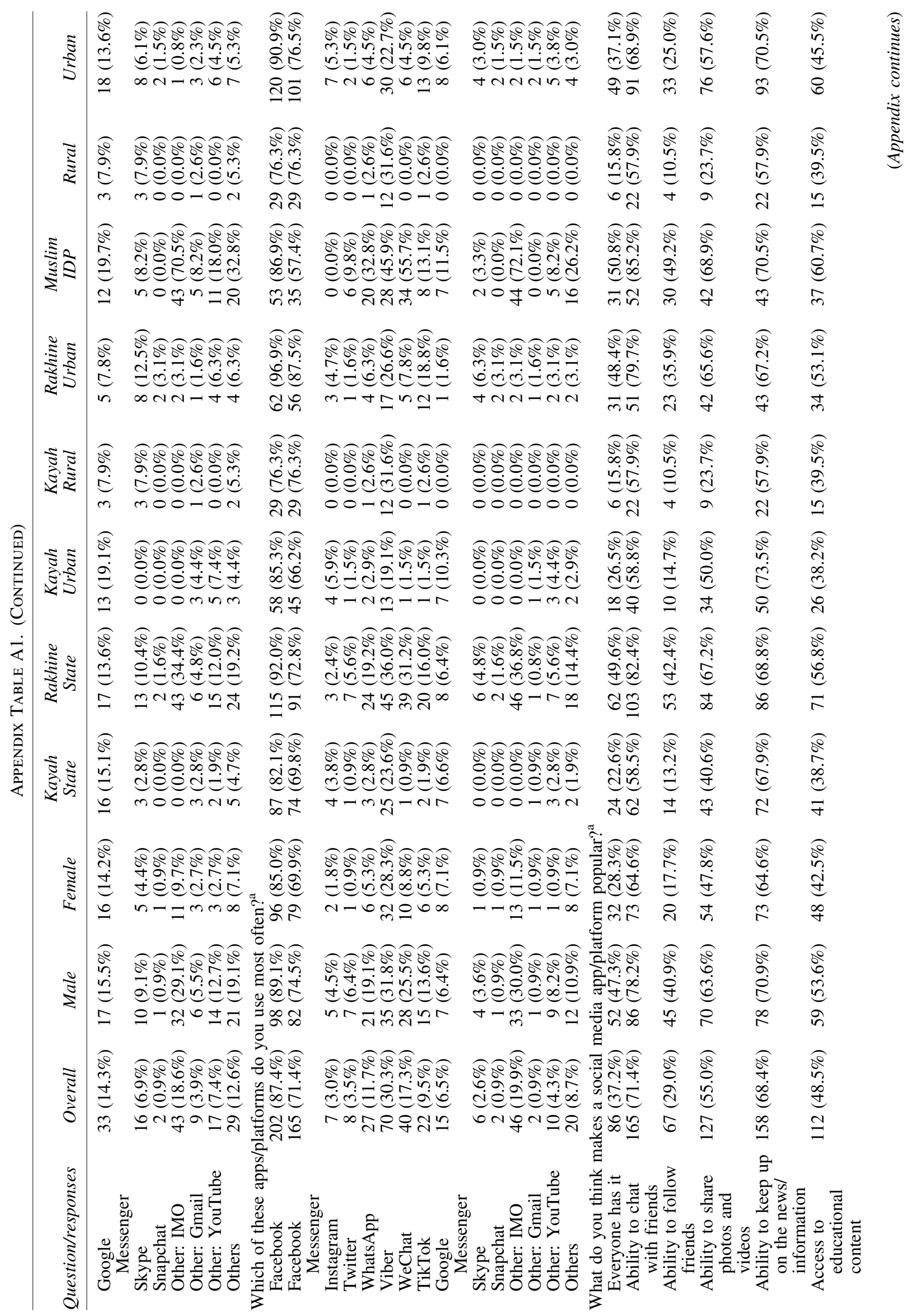




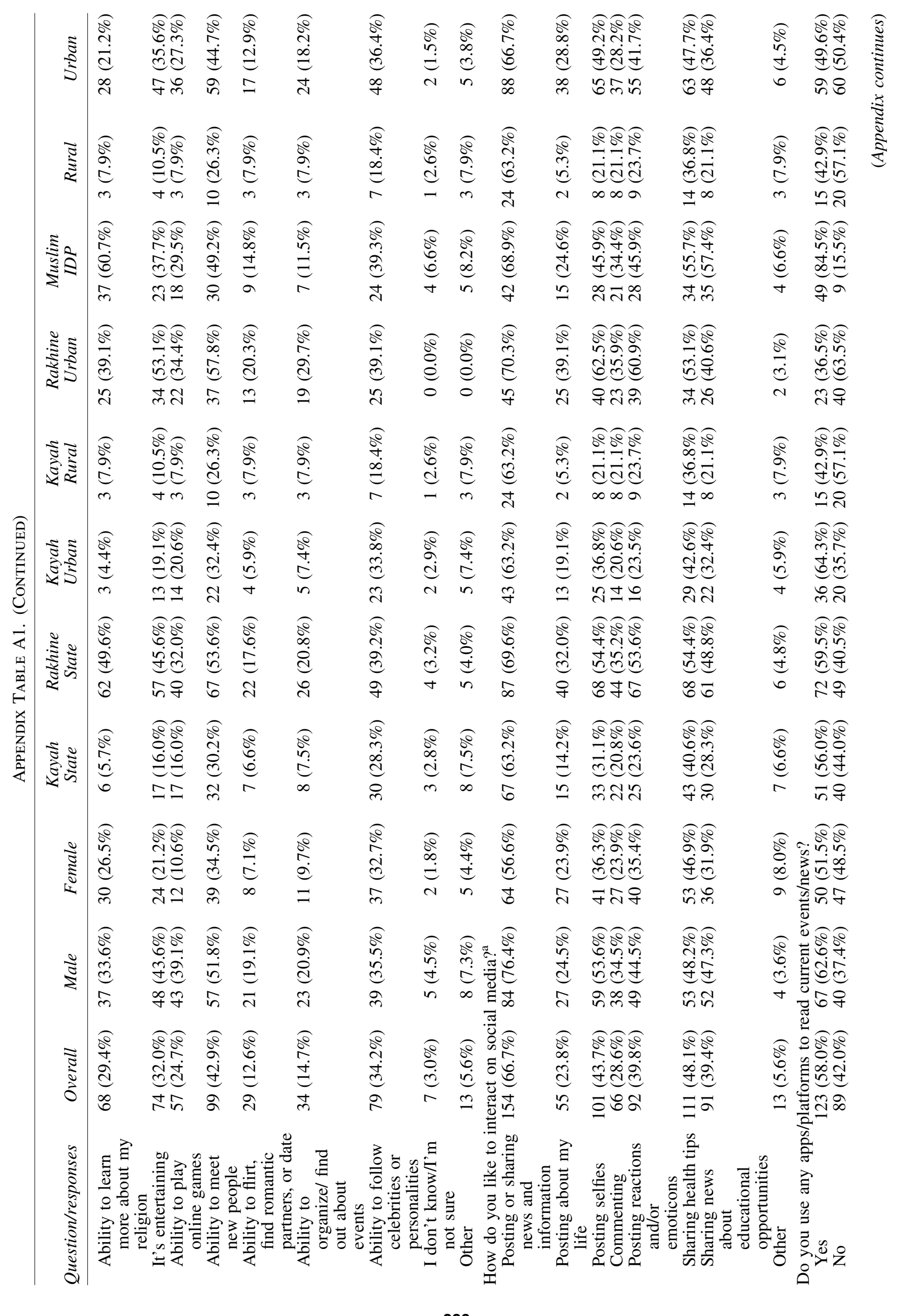




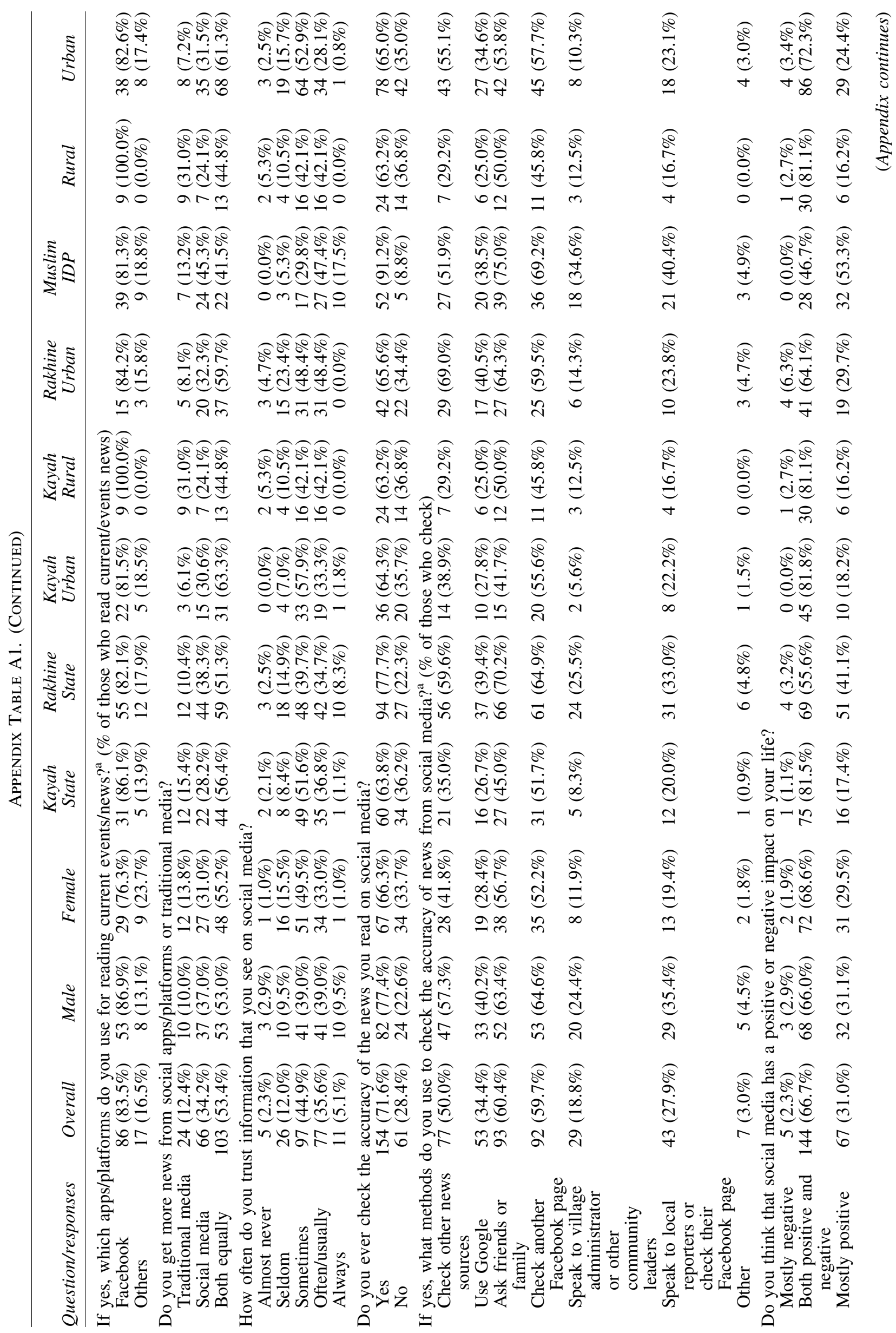




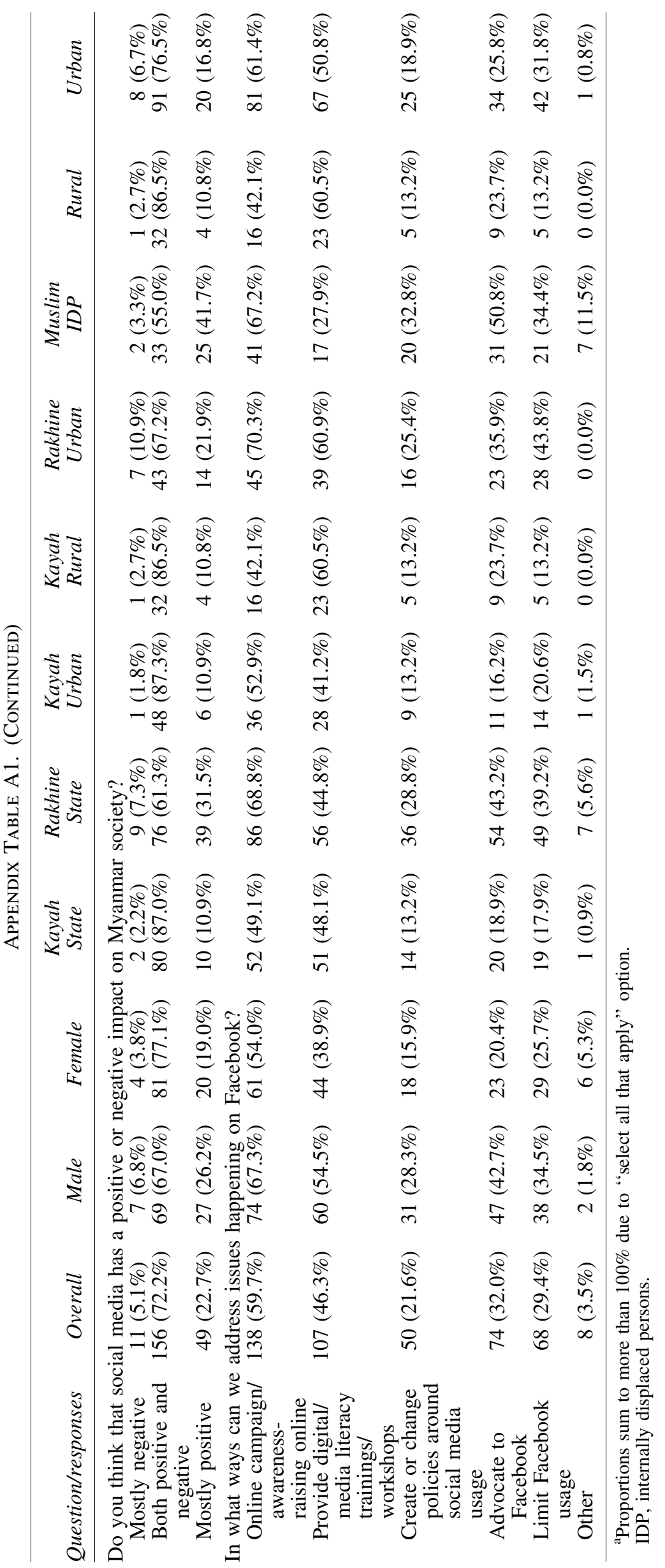

